\title{
Magnetic resonance imaging of pelvic floor dysfunction - joint recommendations of the ESUR and ESGAR Pelvic Floor Working Group
}

\author{
Rania Farouk El Sayed ${ }^{1}$ - Celine D. Alt $^{2}$ • Francesca Maccioni ${ }^{3} \cdot$ Matthias Meissnitzer $^{4}$. \\ Gabriele Masselli $^{5} \cdot$ Lucia Manganaro $^{6}$ - Valeria Vinci ${ }^{6} \cdot$ Dominik Weishaupt $^{7}$. \\ On behalf of the ESUR and ESGAR Pelvic Floor Working Group
}

Received: 25 May 2015 /Revised: 3 May 2016/Accepted: 11 May 2016/Published online: 3 August 2016

(C) The Author(s) 2016. This article is published with open access at Springerlink.com

\begin{abstract}
Objective To develop recommendations that can be used as guidance for standardized approach regarding indications, patient preparation, sequences acquisition, interpretation and reporting of magnetic resonance imaging (MRI) for diagnosis and grading of pelvic floor dysfunction (PFD).

Methods The technique included critical literature between 1993 and 2013 and expert consensus about MRI protocols by the pelvic floor-imaging working group of the European Society of Urogenital Radiology (ESUR) and the European
\end{abstract}

Rania Farouk El Sayed and Celine D. Alt share first authorship

Rania Farouk El Sayed rania729.re@gmail.com

1 Genitourinary \& Pelvic Floor MR Imaging Unit, Department of Radiology, Faculty of Medicine, Cairo University Hospitals, Cairo, Egypt

2 Department of Diagnostic and Interventional Radiology, University Dusseldorf, Medical Faculty, Duesseldorf, Germany

3 Department of Radiological Sciences, Oncology and Pathology Policlinico Umberto I Hospital, Sapienza University Rome, Viale Regina Elena, Rome, Italy

4 Department of Radiology, University Hospital Salzburg, Paracelsus Medical University, Salzburg, Austria

5 Department of Radiology Dea, Umberto I Hospital, Sapienza University of Rome, Viale del Policlinico, Rome, Italy

6 Department of Radiological Sciences, Policlinico Umberto I Hospital, Sapienza University of Rome, Viale Regina Elena, Rome, Italy

7 Institute of Radiology and Nuclear Medicine, Triemli Hospital Zurich, Zurich, Switzerland
Society of Gastrointestinal and Abdominal Radiology (ESGAR) from one Egyptian and seven European institutions. Data collection and analysis were achieved in 5 consecutive steps. Eighty-two items were scored to be eligible for further analysis and scaling. Agreement of at least $80 \%$ was defined as consensus finding.

Results Consensus was reached for $88 \%$ of 82 items. Recommended reporting template should include two main sections for measurements and grading. The pubococcygeal line (PCL) is recommended as the reference line to measure pelvic organ prolapse. The recommended grading scheme is the "Rule of three" for Pelvic Organ Prolapse (POP), while a rectocele and ARJ descent each has its specific grading system.

Conclusion This literature review and expert consensus recommendations can be used as guidance for MR imaging and reporting of PFD.

Key points

- These recommendations highlight the most important prerequisites to obtain a diagnostic PFD-MRI.

- Static, dynamic and evacuation sequences should be generally performed for PFD evaluation.

- The recommendations were constructed through consensus among 13 radiologists from 8 institutions.

Keywords MRI pelvic floor · MR defecography ·

Recommendations · ESUR · ESGAR

\section{Introduction}

Imaging of the female pelvic floor is of rising interest due to an ageing population, harboring an increasing incidence of pelvic floor disorders (PFD) and the rising need for 
comprehensive diagnosis and treatment. The Population Reference Bureau reported the percentage of the population aged 65 and older to be $13 \%$ of the total population in the U.S. in 2010 with an expected increase to $20 \%$ in 2050 , whereas in Europe, the percentage was reported around $18 \%$ in 2010 with an expected increase to $28 \%$ in 2050 [1]. Women that are affected by PFD, often complain most about the impairment of their quality of life and ask for sufficient therapy, which is commonly surgical repair $[2,3]$. Thus, imaging techniques have been constantly developed in recent years to support therapy planning and management. Magnetic resonance imaging (MRI) of the female pelvic floor, particularly, combines high-resolution images with an excellent soft tissue contrast and provides the possibility to assess noninvasively and more objectively a spectrum of possible disorders affecting the pelvic floor in one examination [4-7]. There is general agreement that MRI of the pelvic floor should encompass static and dynamic MR images, whereas dynamic means imaging under maximum stress to the pelvic floor and MR defecography. Static MR images visualize pelvic floor anatomy and defects of the supporting structures, while dynamic MR images visualize pelvic organ mobility, pelvic floor weakness, pelvic organ prolapse (POP) and associated compartment defects [5, 8-11]. Additionally, MRI may diagnose unexpected underlying masked functional abnormalities, which might be discrepant from the dominant symptom and may influence the choice of the surgical technique in around $42 \%$ of patients with different spectra of PFD [12, 13].

Several studies and detailed reviews are published about MRI of the pelvic floor and different acronyms have been used for this examination including static and dynamic MR of the pelvic floor, MR defecography or MR proctography $[4,12,14-16]$. However, to date, there is neither consensus on a standardized imaging protocol nor on a systematic reporting scheme for MR-imaging of PFD. This may be due to the complexity of the anatomy and the functional interaction of the organs with the supporting structures resulting in a broad spectrum of PFD. Another important factor that contributes to this lack of consensus is the fact that PFD is treated by urologists, urogynecologists or proctologists. Consequently, each clinician may manage the patients' condition from a different perspective. Therefore, MR-imaging acquisition varies according to the referring specialty and their rudiments for proper management and treatment decision. The wide range of different available MR protocols and a lack of standardization additionally increase variation between different centers. There is, therefore a necessity for recommendations from an expert panel that clearly defines the minimum prerequisites to obtain a state-of-the-art MR examination of the pelvic floor. This paper reports the recommendations of a panel of expert radiologists in pelvic floor imaging, which are joined in the pelvic floorworking group, which is under the umbrella of the European Society of Urogenital Radiology (ESUR) and the European Society of Gastrointestinal and Abdominal Radiology (ESGAR).

\section{Materials and methods}

The study went through five basic steps that are displayed in Fig. 1.

Step 1 Member recruitment and data sheet creation

Participants for the working group were recruited among ESUR and ESGAR members between 2010 and 2011. The final working group consisted of 13 radiologists from one Egyptian and seven European institutions, all with known expertise in pelvic floor imaging. One member (RFE) created a data sheet to collect technical protocol details of the members' institution. This sheet focused on information about the clinical referrer, patient population, patient preparation, and MR technique (hardware, imaging sequence and imaging parameters).

Step 2 Review of imaging protocols of the participating institutions and data sheet creation for literature review

Data collection, review and discussion of all imaging protocols of the participating institutions took place between 2012 and 2013. During this period modifications on the data sheet were implemented by (RFE) in which full details about both the geometry and the contrast of the static and dynamic MRI during straining as well as those of MRI defecography were added to the original data sheet. The results were presented and discussed in a face-to-face meeting during ECR 2014 during which a consensus was reached to finalize the data sheet for literature research (Appendix 1).

Step 3 Literature search, data collection and analysis

Literature search was conducted in the Medline database for articles published between 1993 and 2013 using the following keywords: "MRI AND Pelvic Floor", "MRI defecography", "MRI pelvic organ prolapse“, "MRI anal incontinence", "MRI stress urinary incontinence", "MRI AND defecography", "Pelvic obstruction syndrome and MRI", "Pelvic outlet obstruction and MRI", "MRI and fecal incontinence", "Pelvic floor and MRI", "MRI and urinary incontinence" and "Pelvic organ prolapse and MRI". 
Fig. 1 Flow chart of the five basic steps of the study

\section{Member recruitment and data sheet creation}

Recruitment among ESUR and ESGAR members between 2010 and 2011

品 The final pelvic floor working group consisted of 13 radiologists from 8 institutions with known expertise in pelvic floor imaging

Creation of a data sheet to collect technical protocol details of the group members' institutions

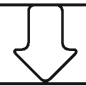

\begin{tabular}{|l|l|}
\hline & $\begin{array}{l}\text { Review of imaging protocols of the participating institutions and data sheet creation for } \\
\text { literature review }\end{array}$ \\
\cline { 2 - 3 } & \multicolumn{1}{|c|}{ Data collection, review and discussion took place between 2012 and 2013} \\
\cline { 2 - 2 } & $\begin{array}{l}\text { Modifications of data sheet including full details about geometry and contrast of sequences were } \\
\text { implemented with discussion in a face-to-face meeting during ECR } 2014\end{array}$ \\
\cline { 2 - 2 } & $\begin{array}{l}\text { Finalisation of the data sheet which included a total of } 88 \text { criteria for literature research } \\
\text { (Appendix 1) }\end{array}$ \\
\hline
\end{tabular}

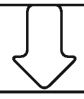

Literature search, data collection and analysis

Medline database was searched for articles published concerning MRI of pelvic floor dysfunction

m etween 1993-2013

Articles were divided into three subchapters for revision including 160 articles about urinary incontinence, 182 articles about pelvic organ prolapse and 172 articles about MR defecography

Three subspecialty leaders gave a final report on the literature review, which were the basis for the construction of a questionnaire

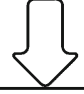

Creation and analysis of a questionnaire

Development and analysis of the questionnaire between 2014 and 2015 (Appendix 2)

Question design: binomial (yes, no), multiple choice, numerical (e.g. ml, seconds), open (free

notes). Number of questions: binomial: 30 ; multiple choice: 52 , numerical: 4 ; open: 3

$\checkmark$ In total, 82 of the 89 questions were completely answered by all panelists and were further

㞻 analysed

S

Answers were scaled according to the individual items

Agreement of at least $80 \%$ was defined as consensus

Consensus finding after the 1 st round was $n=51 / 82$

The answers to the open and numerical questions including e.g. filling volume, sequence duration, slice thickness, repeating of measurements, or alternative techniques were collected and proposed to the members via email.

\begin{tabular}{|l|l|}
\hline & \multicolumn{2}{|c|}{ Discussion and voting for the final consensus recommendations } \\
\cline { 3 - 3 } & Second face-to-face meeting at ECR 2015 \\
& $\begin{array}{l}\text { 2nd round: discussion about those items that did not reach consensus at the first round and } \\
\text { voting afterwards }\end{array}$ \\
\cline { 2 - 3 } & Final consensus could be reached in $88 \%$ of the items $(n=72 / 82)$ \\
\hline
\end{tabular}

Inclusion criteria were original data with full information about the parameters and the protocol of the examination that matched with our final data collection sheet for literature review.
Articles that were not written in English, did not deal with a human study population or lack of information about the performance of the examination were excluded. 
The papers concerning MRI of PFD were divided by (RFE) into the following subchapters: urinary incontinence (160 articles), pelvic organ prolapse (182 articles) and MR-defecography (172 articles). Paper revision and data extraction was divided among participating members into three subspecialty groups (urology, gynaecology and proctology) with one leader for each group (GM, CDA, DW). Each subspecialty leader wrote a final report summarizing the data that was agreed upon. The collected evidence by this literature analysis was used to extract the relevant topics, which should be addressed by the working group panelists in order to construct a questionnaire.

Step 4 Creation and analysis of a questionnaire

From October 2014 to March 2015, one author (CDA) developed a questionnaire to define the most important information and requisites needed to perform MRI of PFD with standardized imaging protocol and reporting scheme. It was finalized in consensus with one author of ESGAR (DW). Since all panelists are using MR systems with a conventional closed-magnet design where the patient can only be examined in supine (lying) body position, procedural and technical aspects of pelvic floor imaging was focused to this type of magnet design. The questionnaire included binomial, multiple choice, numerical and open questions, in total 89 items (Appendix 2). This questionnaire was mailed to all panelists. In total, 82 of 89 questions were answered by all experts and were scaled according to the individual item in question for further analysis. The data obtained were analyzed using descriptive statistics. Agreement of at least $80 \%$ was defined as consensus finding.

Step 5 Discussion and voting for the final consensus recommendations

The second face-to-face meeting took place during ECR congress in 2015. For those questions that did not reach consensus at the first round of the questionnaire analysis, wording was modified to obtain better-defined statements subjected for voting by the experts in a face-to-face meeting. During that meeting the panelists discussed those items and were asked to vote. However, there were items that did not reach consensus but were reported by number of panelist to be important and warrants being included in the recommendations. These items were re-analyzed, and those that were found to be supported by case control or cohort studies from the literature, in particular level of evidence 2 according to the sign criteria, whereas expert opinion is level of evidence 4 (www.sign.ac.uk), were also included in the final recommendation.

\section{Results}

Consensus was reached for $88 \%$ of 82 items and the recommendations regarding indication, patient preparation, imaging protocol, criteria for MRI assessment and reporting were constructed from these.

\section{Indications for MR imaging of pelvic floor dysfunction}

The indications for MR imaging of the pelvic floor that scored the highest number of agreement among the group members and the literature review are rectal outlet obstruction (92\% agreed upon), rectocele (92\% agreed upon), recurrent pelvic organ prolapse (POP) (85\% agreed upon), enterocele ( $85 \%$ agreed upon) and dyssynergic defecation (anismus)(85\% agreed upon) (Table 1).

\section{Patients' preparation and hardware requirements}

Full patients' history of pelvic floor disorder should be taken prior to scanning (consensus $100 \%$ ). The patient should be examined at least in a $1.5 \mathrm{~T}$ MRI unit with a phased array coil, as this is the most agreed-upon field strength (consensus $100 \%$ ). The patient is examined in

Table 1 Most common indications for MR-imaging of pelvic floor dysfunction*

\begin{tabular}{ll}
\hline Indications & $\begin{array}{l}\text { Score of agreement } \\
\text { achieved** }\end{array}$ \\
\hline Anterior compartment & $7 / 13$ \\
$\quad$ Stress urinary incontinence & $7 / 13$ \\
$\quad$ Recurrence after surgical POP repair & \\
Middle compartment & $11 / 13$ \\
Recurrence after surgical POP repair & $11 / 13$ \\
Enterocele / Peritoneocele & $7 / 13$ \\
POP & \\
Posterior compartment & $12 / 13$ \\
Outlet obstruction & $12 / 13$ \\
Rectocele & $11 / 13$ \\
Anismus & $10 / 13$ \\
Fecal incontinence & $9 / 13$ \\
Recurrence after surgical POP repair & $8 / 13$ \\
Rectal intussusception & \\
Non-specific compartment & $7 / 13$ \\
Pelvic pain / perineal pain & $7 / 13$ \\
Descending perineal syndrome & \\
\hline POP pelvic organ prolapse & \\
* The indications of MRI in each compartment are listed in a descending \\
order from those that scored the highest number of agreement among both \\
the group members and the literature review \\
** Number of group members $n=13$
\end{tabular}


the supine position with the knees elevated (e.g. on a pillow with firm consistency) as this was found to facilitate straining and evacuation (consensus $100 \%$ ). The coil should be centered low on the pelvis to ensure complete visualization of prolapsed organs $[4,15]$. The bladder should be moderately filled, therefore voiding 2 hours before the examination is recommended (consensus $100 \%)$.

Prior to the examination the patient should be trained on how to correctly perform the dynamic phases of the examination and the evacuation phase (consensus $100 \%$ ). The patient is instructed to squeeze as if trying to prevent the escape of urine or feces and hold this position for the duration of the sequence. For maximum straining, the patient is instructed to bear down as much as she/he could, as though she/he is constipated and is trying to defecate [15]. For the evacuation phase, the patient should be instructed to repeat the evacuation process until the rectum is emptied.

To decrease possible patient's discomfort, a protective pad or a diaper pant should be offered to the patient, which helps to increase patients' compliance during dynamic and evacuation phases (consensus $100 \%$ ). No oral or intravenous contrast is necessary [15].

The rectum should be distended in order to visualize the anorectal junction (ARJ), rectoceles and intussusceptions, and to evaluate the efficacy of rectal evacuation (consensus $100 \%$ ). Ultrasound gel is the recommended medium to distend the rectum, however, the amount varies between 120 to $250 \mathrm{cc}$ (consensus $100 \%$ ). For rectal distension a large amount of gel (180-200 cc) likely improves the capacity of the patient to defecate. A checklist for the recommended patients' preparation is listed in (Table 2).

A rectal cleansing enema prior to the examination is helpful but reached no consensus to be generally performed. Vaginal filling with $20 \mathrm{cc}$ ultrasound gel is helpful for better demarcation, however, it reached no consensus for general performance and its application may be limited due to social or religious backgrounds.

\section{MR-imaging protocol}

The recommended MR-imaging protocol is summarized in (Table 3). The protocols consists of static MR sequences and dynamic sequences, whereas dynamic means imaging during straining, squeezing and during evacuation or defecation.

According to the concordance of experts and level of evidence, high resolution T2-weighted images (T2WI) (e.g. Turbo Spin Echo, TSE ; Fast Spin Echo, FSE; Rapid Acquisition with Relaxation Enhancement, RARE)

Table 2 Checklist for the recommended patients' preparation and MR-Imaging protocols

\begin{tabular}{|c|c|c|}
\hline Done & $\begin{array}{c}\text { Concordance } \\
\text { of experts } \\
n=8\end{array}$ & $\begin{array}{l}\text { Level of } \\
\text { Evidence* }\end{array}$ \\
\hline
\end{tabular}

\section{A Patients' preparation}

Equipment: preferable 1.5 T magnet and phased array coil

Take patients' history of pelvic floor disorder

Ask the patient to void $2 \mathrm{~h}$ before the examination

Train the patient on how to perform squeezing, straining and evacuation

Use a diaper for protection

Do rectal filling with ultrasonic gel

Examine the patient in supine position with elevated knees on a high pillow

\begin{tabular}{|c|}
\hline $100 \%$ \\
\hline $100 \%$ \\
\hline $100 \%$ \\
\hline $100 \%$ \\
\hline $100 \%$ \\
\hline $100 \%$ \\
\hline $100 \%$ \\
\hline
\end{tabular}

\section{B MR-imaging protocol}

\section{Recommended static sequences}

T2-weighted TSE, FSE, RARE in sagittal, transverse and coronal plane

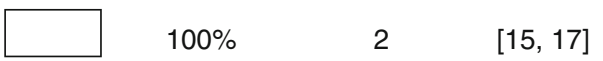

2 Recommended dynamic SSFP or BSFP sequences in sagittal plane

Straining phase

Evacuation phase

Squeezing phase

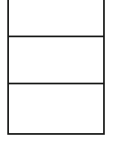

$100 \%$
$100 \%$
$88 \%$

2

$100 \% \quad 2$

$[16,17,19]$

$\overline{B S F P}$ balanced state free precession, $F S E$ fast spin echo, RARE rapid acquisition with relaxation enhancement, $S S F P$ steady state free precession, $T S E$ turbo spin echo

* Level of evidence 2 = based on systematic reviews, case control or cohort studies; Level of evidence 4 = based on expert opinion (www.sign.ac.uk) 


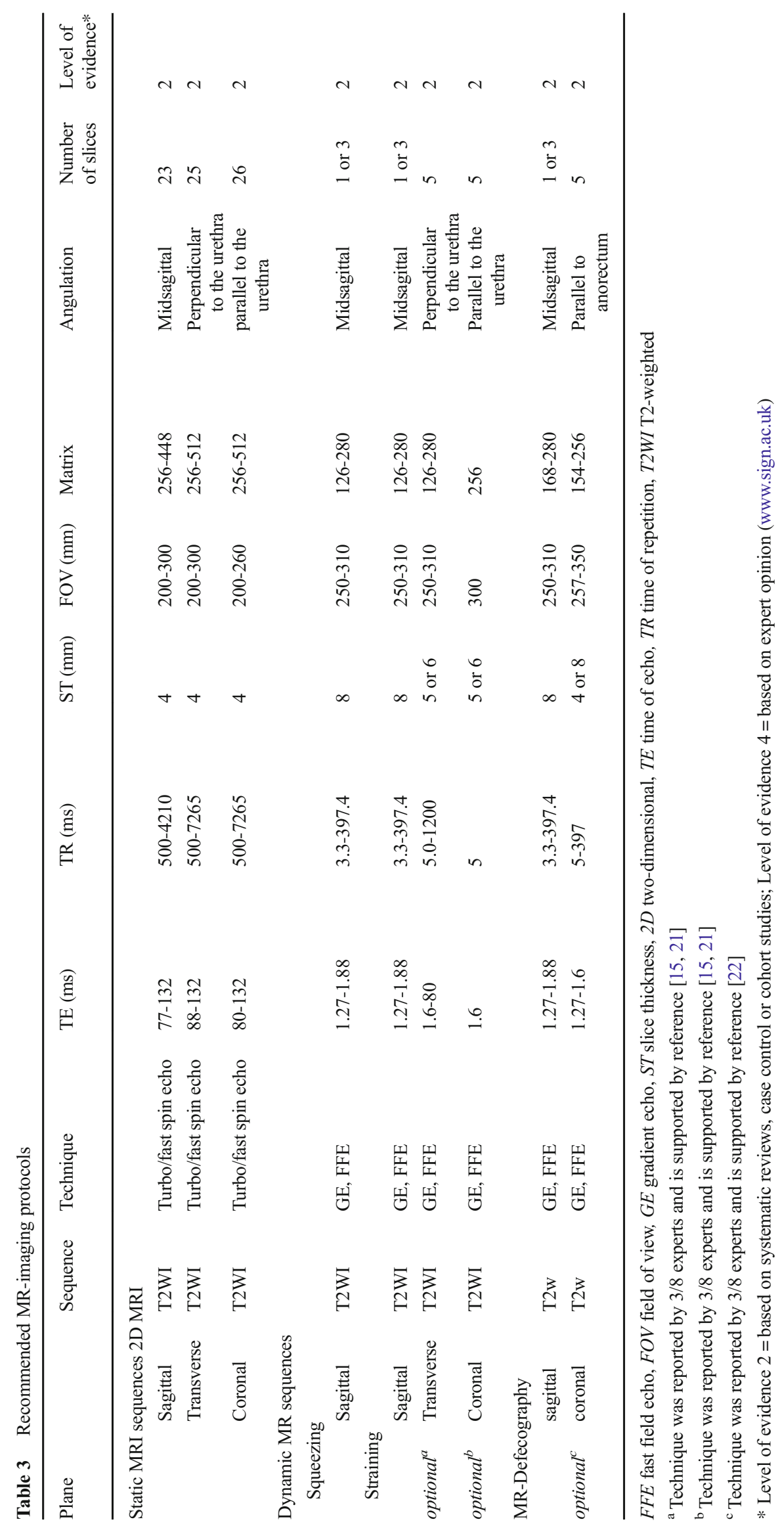




\begin{tabular}{|c|c|c|c|c|}
\hline & 1. & 2. & 3. & 4. \\
\hline 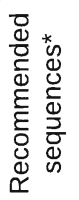 & $\begin{array}{l}\text { Imaging at rest in } \\
\text { three planes }\end{array}$ & $\begin{array}{l}\text { Imaging during squeezing } \\
\text { in sagittal plane }\end{array}$ & $\begin{array}{l}\text { Imaging during maximum } \\
\text { straining in sagittal plane }\end{array}$ & $\begin{array}{l}\text { Imaging during } \\
\text { evacuation of the rectal } \\
\text { gel in sagittal plane }\end{array}$ \\
\hline
\end{tabular}

\begin{tabular}{|c|c|c|c|c|}
\hline 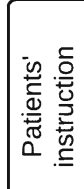 & $\begin{array}{l}\text { Patient is asked to } \\
\text { breath normal } \\
\text { without requested } \\
\text { manoeuvers }\end{array}$ & $\begin{array}{l}\text { Patient is asked to } \\
\text { squeeze as if trying to } \\
\text { prevent the escape of } \\
\text { urine or faeces and hold } \\
\text { this position for the } \\
\text { duration of the sequence }\end{array}$ & $\begin{array}{l}\text { Patient is asked to bear } \\
\text { down as much as she could, } \\
\text { as though she is constipated } \\
\text { and tries to defecate and } \\
\text { hold this position for the } \\
\text { duration of the sequence }\end{array}$ & $\begin{array}{l}\text { Patient is asked to } \\
\text { evacuate the rectum } \\
\text { continously and to relax } \\
\text { the pelvic floor before the } \\
\text { next evacuation phase }\end{array}$ \\
\hline
\end{tabular}

\begin{tabular}{|c|c|c|c|c|}
\hline 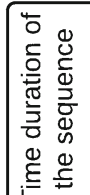 & $\begin{array}{l}\text { 2-3 minutes each } \\
\text { plane }\end{array}$ & $\begin{array}{l}\text { Less than } 20 \text { seconds as } \\
\text { the patient needs to hold } \\
\text { the breath }\end{array}$ & $\begin{array}{l}\text { Less than } 20 \text { seconds as } \\
\text { the patient needs to hold } \\
\text { the breath }\end{array}$ & $\begin{array}{l}\text { The sequence should be } \\
\text { repeated until the rectum } \\
\text { is emptied (time duration } \\
\text { of one evacuation trial is } \\
\text { around } 50 \text { seconds) }\end{array}$ \\
\hline
\end{tabular}

\begin{tabular}{|c|c|c|}
\hline \multirow{2}{*}{ 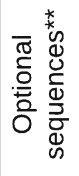 } & $\begin{array}{l}\text { Imaging during maximum } \\
\text { straining in transverse plane }\end{array}$ & \multirow{2}{*}{$\begin{array}{l}\text { Imaging during evacuation } \\
\text { in coronal plane }\end{array}$} \\
\hline & $\begin{array}{l}\text { Imaging during maximum } \\
\text { straining in coronal plane }\end{array}$ & \\
\hline
\end{tabular}

* $100 \%$ agreement of expert opinion and level of evidence 2 ; ${ }^{\star \star}$ Level of evidence 2 without expert consensus (3/8)

Fig. 2 Schedule of the recommended imaging sequences, the instruction given to the patient and the time duration per sequence

in three planes are recommended for static images, whereas steady state (e.g. FISP, GRASS, FFE, PSIF, SSFP, T2-FFE) or balanced state free precession sequence (e.g. trueFISP, FIESTA, B-FFE) in sagittal plane is recommended for dynamic sequences (squeezing and straining) and evacuation sequence (consensus $100 \%$ ). The dynamic sequence should not exceed 20 seconds each, as breath holding is required (consensus $100 \%$ ). The evacuation sequence

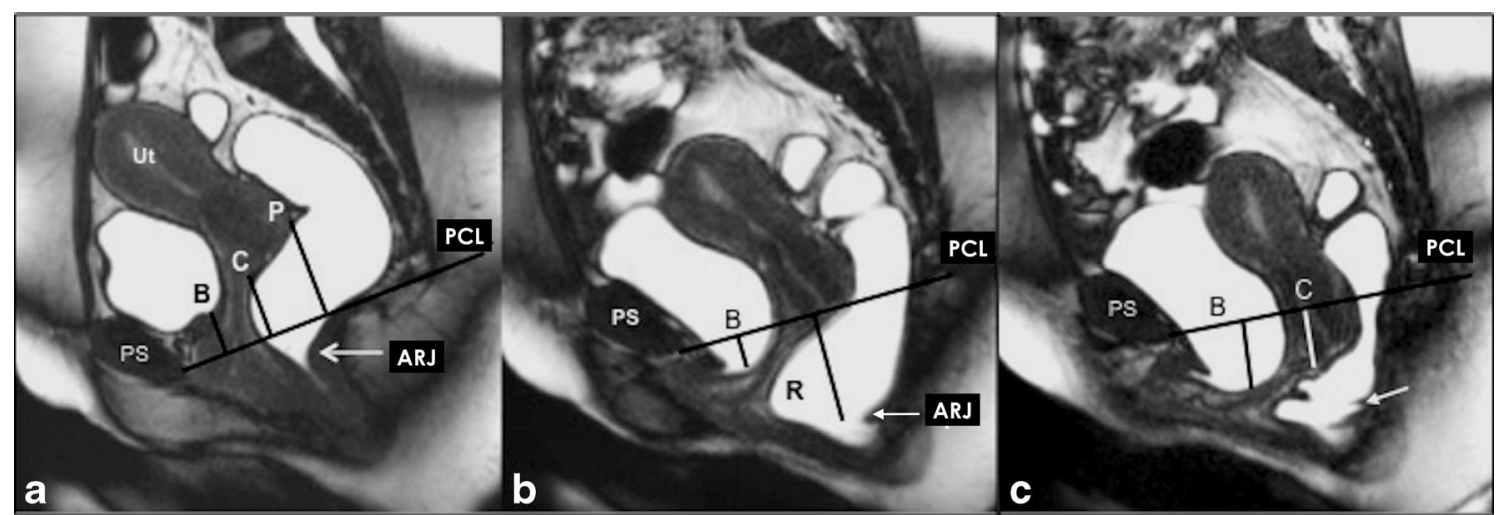

Fig. 3 Basic measurements. a. Dynamic Balanced Fast Field Echo (BFFE) sequence in the midsagittal plane at rest shows how to plot the basic measurements of pelvic organ prolapse. The pubococcygeal line (PCL), drawn on sagittal plane from the inferior aspect of the pubic symphysis (PS) to the last coccygeal joint. After defining the PCL, the distance from each reference point is measured perpendicularly to the PCL at rest and at maximum straining. B; bladder base, C; cervix, P; pouch of Douglas, ARJ; Anorectal junction. Measured values above the reference line have a minus sign, values below a plus sign. b. Dynamic BFFE during maximum straining shows the movement of the organs compared to their location at rest. It is recommend to give the difference of the values at rest and during straining for each organ-specific reference point (pelvic organ mobility). R; Rectocele, ARJ; Ano-Rectal Junction. c. MRI defecography (BFFE) in the mid sagittal plane during evacuation of the intra-rectal gel. Dynamic MR imaging during evacuation is mandatory, because certain abnormalities and the full extent of POP are only visible during evacuation. In this case compared to the maximum staining phase it is obvious that there is increase of the degree of the pelvic organ descent and development of new pathology including the loss of urine and the detection of masked intussusception, which was detected only during excavation (white arrow) 


\section{Done Concordance Level of $\underset{n=8}{\text { of experts Evidence* }}$}

Reference

\section{A Measurements}

1 Basic measurements for all compartments

Determine PCL

Determine organ-specific reference points

Measure the descent of reference points below the PCL

\begin{tabular}{|c|ccc|}
\hline $100 \%$ & 2 & {$[15,24]$} \\
\hline $100 \%$ & 2 & {$[25]$} \\
$100 \%$ & 2 & {$[15,26]$}
\end{tabular}

\section{Measurements for posterior compartment}

Measure the bulging of the anterior rectal wall at evacuation phase/straining phase Measure the ARA at rest - squeezing phase - straining phase/evacuation phase

\begin{tabular}{|ccc}
\hline $100 \%$ & 2 & {$[15,20]$} \\
$100 \%$ & 2 & {$[16,27]$}
\end{tabular}

\section{B Reporting}

1 Basic reporting for all compartments

Report values above the PCL as negative and below as positive

Report pelvic organ mobility

\begin{tabular}{|rrr|}
\hline $100 \%$ & 2 & {$[28]$} \\
$100 \%$ & 2 & {$[8,25]$}
\end{tabular}

2 Reporting for anterior compartment

Report loss of urine at straining phase

Report urethral mobility at straining phase

\begin{tabular}{|lll|}
\hline $88 \%$ & 2 & {$[15]$} \\
\hline $88 \%$ & 2 & {$[29]$}
\end{tabular}

3 Reporting for middle compartment

Report uterine descent

Report the content of a present enterocele

\begin{tabular}{|l|ll|}
\hline $100 \%$ & 4 & {$[15]$} \\
\hline $100 \%$ & 4 & {$[15]$}
\end{tabular}

\section{Reporting for posterior compartment}

Report presence of a rectal intussusception

Evaluate time-effective rectal evacuation

Point out the change of ARA

\begin{tabular}{|c|c|}
\hline $100 \%$ & 2 \\
$88 \%$ & 2 \\
$100 \%$ & 4
\end{tabular}

\section{Grading}

\section{Anterior compartment}

Use the "rule-of-three' grading for cystocele

Report cystocele as pathological starting from ${ }^{\circ} \mathrm{I}$

\begin{tabular}{|rrr|}
\hline $100 \%$ & 2 & {$[32,33]$} \\
$88 \%$ & 4 & {$[33]$}
\end{tabular}

\section{Middle compartment}

Use the "rule-of-three' grading for uterine prolapse and enteroceles

Report POP as pathological starting from ㅇI

\begin{tabular}{|l|l|}
\hline $100 \%$ & 2 \\
$88 \%$ & 4
\end{tabular}

\section{Posterior compartment}

Use the grading for Anorectal Junction descent (ARJ) starting at $3 \mathrm{~cm}$ below the PCL

Report a rectocele as pathological starting from ${ }^{\circ} \mathrm{I}$

Use the "rule-of-two" grading for rectoceles

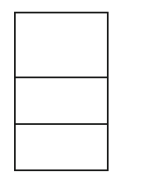

$\begin{array}{ccc}100 \% & 2 & {[19,36]} \\ 100 \% & 2 & {[19,20]} \\ 88 \% & 2 & {[16,19]}\end{array}$

$P C L$ pubococcygeal line, $A R A$ anorectal angle, $P O P$ pelvic organ prolapse, $A R J$ anorectal junction

* Level of evidence 2 = based on systematic reviews, case control or cohort studies; Level of evidence 4 = based on expert opinion (www.sign.ac.uk)

should be repeated until the rectum is emptied to exclude rectal intussusception (total time duration around 2-3 minutes)(consensus $100 \%$ ). Dynamic MR imaging during evacuation is mandatory, because certain abnormalities 
and the full extent of POP is only visible during evacuation. Optional MRI sequences can be added and acquired for further assessment of pelvic floor relaxation. These include axial and coronal dynamic sequences during maximum straining. Illustration of all the recommended imaging sequences and patients' maneuvers is summarized in (Fig. 2).

Since the performance of adequate pelvic stress during the dynamic sequences is important in order to assess the full extent of PFD, quality control of the study is essential. The study can only be considered diagnostic if a clear movement of the abdominal wall is seen during squeezing and straining. If no evacuation of rectal content at all or a delayed evacuation time (more than 30 seconds to evacuate $2 / 3$ of the rectal content) is present, anismus should be considered (consensus $88 \%$ ) [23].

\section{Image analysis, measurements, grading and MRI report}

\section{Image analysis}

A clear consensus was reached that the assessment of a MR study of the pelvic floor should include analysis of static images for detection and classification of structural abnormalities. The dynamic images are analyzed with regard to functional abnormalities that are assessed by metric measurements of the three compartments of the pelvic floor (consensus $100 \%$ ) (Fig. 3). The measurements help to recognize and grade the extent of POP and pelvic floor relaxation (PFR), as well as they are used to grade anterior rectoceles and enteroceles (consensus $100 \%$ ). Both static and dynamic MRI findings as well as the results of the metric measurements should be reported in a structured MR reporting scheme (consensus $100 \%$ ) (Table 4).

Due to the different views of the clinical specialists involved in the treatment of PFD, it is suggested to consider adapting the MRI reporting scheme according to the specialty of the referring physician. A proposal for a specialty-based MRI report is given in (Table 5).

\section{Measurements}

The pubococcygeal line (PCL), drawn on sagittal plane from the inferior aspect of the pubic symphysis to the last coccygeal joint, is recommended as reference line to measure POP (consensus $100 \%$ ). It shows the highest inter- and intraobserver reliability of MRI measurements in women with POP of the anterior and middle compartment compared to all proposed reference lines in the literature with an intercorrelation coefficient (ICC) between 0.70-0.99 (Fig. 3a) [14, 37, 38].

After defining the PCL, the distance from each reference point is measured perpendicularly to the PCL at rest and at maximum strain (consensus $100 \%$ ) [26, 29]. In the anterior compartment, the organ-specific reference point is the most
Table 5 Specialty-based MRI reporting scheme

Urologic patients

Report of pathologies if present

During dynamic sequences

Loss of urine through the urethra at maximum straining

Hypermobility of the urethra

Kinking of the vesicourethral junction

Uretherocele

Cystocele; type (distension or displacement), size $(\mathrm{cm})$, grade

On static images

Damage of the supporting urethral ligaments

Avulsion or defect of the puborectal muscle

Measurements

Pelvic organ mobility

Pelvic floor relaxation

Iliococcygeus angle

Hiatal dimensions

Further evaluation

Additional findings regarding the pelvic organs*

Coexistent middle and posterior compartment disorders

(Uro)gynecologic patients

Report of pathologies, if present:

During dynamic sequences

Cystocele; type (distension or displacement), size $(\mathrm{cm})$, grade

Uterine prolapse: partial or total

Enterocele: type (content of the peritoneal sac), size $(\mathrm{cm})$, grade

On static images

Avulsion or defect of the puborectal muscle

Measurements

Pelvic organ mobility

Pelvic floor relaxation

Iliococcygeus angle

Hiatal dimensions

Further evaluation

Additional findings regarding the pelvic organs*

Coexistent anterior and posterior compartment disorders

Proctologic patients

Report of pathologies, if present:

During dynamic sequences

Rectocele: type (anterior or rarely posterior) size $(\mathrm{cm})$, grade

Rectal mucosal invagination or prolapse: differentiation, extent, grade

Rectal descent: distance to PCL (cm), grade

Enterocele: type (content of the peritoneal sac), size $(\mathrm{cm})$, grade

Lack of changes of ARA

Insufficient opening of the anal canal with inadequate rectal emptying during evacuation

Rectal intussusception

Measurements

Rectocele

Rectal decent

ARA

Pelvic organ mobility

Pelvic floor relaxation

Further evaluation

Additional findings regarding the pelvic organs*

Coexistent anterior and middle compartment disorders

$A R A$ anorectal angle, $P C L$ pubococcygeal line, $P F D$ pelvic floor disorder.

* e.g. adnexal lesions, uterine diseases, urethral and bladder diverticula, diverticulosis, diverticulitis

inferior aspect of the bladder base (B), in the middle compartment, the organ-specific reference point is the anterior cervical lip (most distal edge of the cervix)(C), or the vaginal vault in case of previous hysterectomy $(\mathrm{V})$, and in the posterior 
compartment, the organ-specific reference point is the anorectal junction (ARJ) (consensus $100 \%$ ) (Fig. 3a) [15, $16,20,25,29,39]$. Measured values above the reference line have a minus sign, values below a plus sign (consensus $100 \%)$ [25].

Reporting of the movement of the organs compared to their location at rest is stated to give more valuable information for the referrer than a grading system alone $[8,25]$. We therefore recommend giving the difference of the values at rest and during straining for each organ-specific reference point (pelvic organ mobility)(consensus $100 \%$ ) (Fig 3a, b).
A rectocele is diagnosed as an anterior rectal wall bulge and it is measured during maximum straining and evacuation (Fig 4). Typically, a line drawn through the anterior wall of the anal canal is extended upward, and a rectal bulge of greater than $2 \mathrm{~cm}$ anterior to this line is described as a rectocele (consensus $100 \%$ ) $[28,34]$. The anorectal angle (ARA) should be drawn along the posterior border of the rectum and a line along the central axis of the anal canal on sagittal plane (Fig. 4b) at rest, squeezing and maximum straining (consensus $100 \%$ ) [20, 27].

Pelvic floor relaxation (PFR) often coexists with POP, but it is a different pathologic entity. For quantification of the
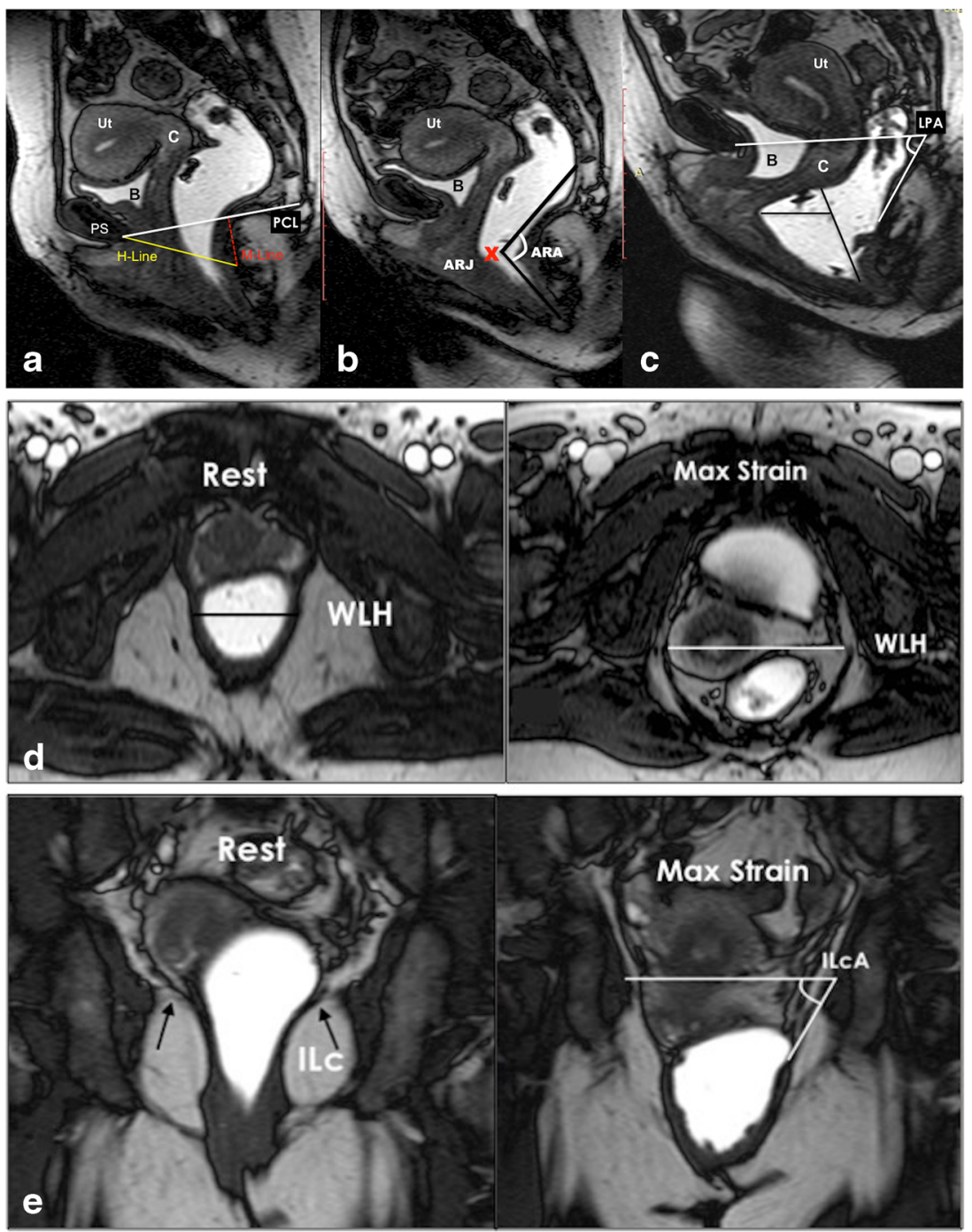

Fig. 4 Pelvic floor relaxation and posterior compartment measurements. a,b,c Dynamic Balanced Fast Field Echo (BFFE) sequence in the midsagittal plane at rest (a), mild (b), and maximum straining (c). (a) shows how to quantify the pelvic floor laxity. The H-line extends from the inferior aspect of the pubic symphysis to the anorectal junction, the Mline is dropped as a perpendicular line from the pubococcygeal line (PCL) to the posterior aspect of the H-line. (b) Demonstrates the anorectal angle (ARA) drawn along the posterior border of the rectum and a line along the central axis of the anal canal on sagittal plane. ARJ; Ano-Rectal Junction. (c) Shows how to measure and diagnose a pathological rectocele: a line drawn through the anterior wall of the anal canal is extended upward, and a rectal bulge of greater than $2 \mathrm{~cm}$ anterior to this line is described as a rectocele $(\mathrm{R})$. The levator plate angle (LPA) is enclosed between the levator plate and the PCL. d,e. Dynamic Balanced Fast Field Echo (BFFE) sequence in axial (d) and coronal (e) plane at rest and during maximum straining. In the axial plane the width of the levator hiatus is enclosed between the puborectalis muscle slings. On the coronal plane, the iliococcygeus angle is measured between the iliococcygeus muscle and the transverse plane of the pelvis in posterior coronal images at the level of the anal canal 
weakness of the levator ani and to reflect pelvic floor laxity, five measurements can be performed [15], however, it reached no consensus to measure it routinely. The length of the hiatus (H-line), the descent of the levator plate (M-line) and the levator plate angle are evaluated in the sagittal plane (Fig 4a, c), whereas the transverse width of the levator hiatus and the iliococcygeus angle are assessed in the axial and coronal plane during maximum straining(Fig. 4e,d) [15]. Table 6 provides an overview of the entire spectrum of the published reference values for quantitative MR-measurements of the pelvic floor.

\section{Grading}

The 'Rule of three' is the recommended grading system in the anterior and middle compartment starting at $1 \mathrm{~cm}$ below the PCL (Table 4) $[15,16,32,34,40]$. This is based on the fact that the pelvic floor may descend and widen up to $2 \mathrm{~cm}$ during abdominal pressure. Consequently, the pelvic organs follow the movement of the pelvic floor inferiorly but without protrusion through their respective hiatuses [4]. The bladder base, particularly, may descend up to $1 \mathrm{~cm}$ below the PCL during straining in continent women and should not be stated as a cystocele (consensus $100 \%$ ) [24, 34].

The "Rule of two" is recommended for grading the anterior rectal wall bulge in rectoceles (consensus $100 \%$ ) (Table 4)
[16;23;25;26;31]. It should be reported as pathological from grade ${ }^{\circ} \mathrm{II}$, as a grade ${ }^{\circ} \mathrm{I}$ rectocele can be observed in nearly 78 $99 \%$ of parous women, while rarely in men $[20,28,41]$.

Anorectal junction descent (ARJD) is graded (grade ${ }^{\circ}$ I) between 3 and $5 \mathrm{~cm}$ below the PCL, and (grade ${ }^{\circ} \mathrm{II}$ ) with at least $5 \mathrm{~cm}$ (consensus $100 \%$ ) [36].

Small intussusceptions of the rectal wall are considered to be normal findings during defecation, observed in nearly $80 \%$ of healthy subjects [41].

\section{Reporting other functional abnormalities and structural defects}

\section{Functional abnormalities on dynamic MR images}

Loss of urine through the urethra during maximum straining records urinary incontinence (UI) and should be reported if present (consensus $88 \%$ )[15]. Urethral hypermobility as a predictor for UI should be reported if present (consensus $88 \%$ ) [29]. If a cystocele is present, the differentiation of a distention or a displacement cystocele can be made, which is helpful for therapy planning, however it reached no consensus for general reporting [42].

If an enterocele is present, the report should include the content of the peritoneal sac, as clinical examination alone
Table 6 Overview of the published reference values for quantitative MR-measurements of the pelvic floor

\begin{tabular}{|c|c|c|}
\hline Parameters & $\begin{array}{l}\text { Reference value } \pm \\
\text { standard deviation }\end{array}$ & Reference \\
\hline \multicolumn{3}{|l|}{ Anterior compartment } \\
\hline Bladder base position (according to PCL) at rest & $-2.3 \pm 0.46 \mathrm{~cm}$ & [39] \\
\hline $\begin{array}{l}\text { Bladder base position } \\
\text { (according to PCL) during straining }\end{array}$ & $0.81 \pm 1.11 \mathrm{~cm}$ & [39] \\
\hline \multicolumn{3}{|l|}{ Middle compartment } \\
\hline $\begin{array}{l}\text { Anterior cervical lip position } \\
\text { (according to PCL) at rest }\end{array}$ & $4.31 \pm 0.78 \mathrm{~cm}$ & [39] \\
\hline $\begin{array}{l}\text { Anterior cervical lip position } \\
\text { (according to PCL) during straining }\end{array}$ & $-0.79 \pm 1.65 \mathrm{~cm}$ & [39] \\
\hline \multicolumn{3}{|l|}{ Posterior compartment } \\
\hline $\begin{array}{l}\text { Anterior bulge of the rectal wall during } \\
\text { straining (rectocele) }\end{array}$ & $2.6 \pm 0.6 \mathrm{~cm}$ & {$[39]$} \\
\hline Ano rectal junction (ARJ) at rest & $\begin{array}{c}\leq 3 \mathrm{~cm} \text { below the PCL } \\
0.53 \pm 0.99 \mathrm{~cm}\end{array}$ & {$[34,39]$} \\
\hline ARJ during squeezing & Elevation of ARJ & {$[36]$} \\
\hline ARJ during straining & $2.99 \pm 1.03 \mathrm{~cm}$ & [39] \\
\hline Anorectal angle (ARA) at rest & $85-95^{\circ}$ & {$[31,39]$} \\
\hline & $93^{\circ} \pm 4.8^{\circ}$ & \\
\hline ARA during squeezing & $71^{\circ}$ sharpening of $10-15^{\circ}$ & {$[16,27]$} \\
\hline ARA during straining or defecation & $\begin{array}{l}103^{\circ} 15-25^{\circ} \text { more obtuse } \\
108^{\circ} \pm 14.7^{\circ}\end{array}$ & {$[16,27,39]$} \\
\hline \multicolumn{3}{|l|}{ Measurements for quantification of the pelvic floor laxity } \\
\hline H-line (hiatus) during straining & $5.8 \pm 0.5 \mathrm{~cm}$ & {$[15]$} \\
\hline M-line (descent of $\mathrm{H}$-line to $\mathrm{PCL}$ ) during straining & $1.3 \pm 0.5 \mathrm{~cm}$ & {$[15]$} \\
\hline Levator plate angle during straining & $11.7 \pm 4.8^{\circ}$ & {$[15]$} \\
\hline Iliococcygeus angle at rest & $20.9 \pm 3.5^{\circ}$ & [15] \\
\hline Iliococcygeus angle during straining & $33.4 \pm 8.2^{\circ}$ & {$[15]$} \\
\hline Transverse diameter of levator hiatus at rest & $3.3 \pm 0.4$ & {$[15]$} \\
\hline Transverse diameter of levator hiatus during straining & $4.5 \pm 0.7 \mathrm{~cm}$ & [15] \\
\hline
\end{tabular}




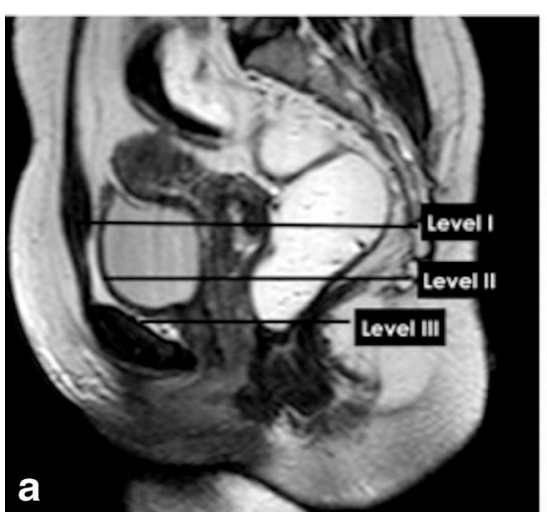

Fig. 5 Functional three -part pelvic supporting system. a,b. Static T2W Turbo-Spin Echo (TSE) MR images in sagittal and axial plane. (a) Sagittal MR image illustrating the levels of the endopelvic fascia (paracolpium) that attaches the upper vagina to the pelvic walls, it is divided into three levels. Level I (suspension); the portion of the vagina adjacent to the cervix (the cephalic $2-3 \mathrm{~cm}$ of the vagina) functionally it provides the upper vaginal support. Level II (attachment); located in the mid portion of the vagina, it stretches the vagina transversely between

may have shortcomings in identifying the content (consensus $100 \%)[5,20,22,31,43]$.

The end of evacuation phase is important to identify intussuception (Fig. 3c) [30].

The change of the ARA during dynamic and evacuation sequence compared to the ARA at rest expresses the functioning of the puborectal muscle. In particular, the ARA should sharpen during squeezing and should become more obtuse during straining and evacuation [16, 27, 39]. We recommend to report the individual function, as the literature presents with a widespread of normal reference values (consensus $100 \%$ ).

\section{Structural defects on static MR images}

Description of structural defects and anatomical abnormalities, that are assessed in static T2WI are more likely specialty-based PFD-related questions from the referrer (Table 5). The functional three-part pelvic supporting system (Fig. 5) includes the urethral support system, which maintains urinary continence; the vaginal support system, which prevents prolapse; and the anal sphincter complex that maintains anal continence. Urethral support system defects may include urethral ligament defect and / or distortion, level III endopelvic fascial defects, or puborectalis muscle detachment(Fig. 5b), disruption, atrophy or avulsion $[15,18$, $21,33,44-46]$. The spectrum of vaginal support system abnormalities includes level I and II paravaginal fascial defects and/or iliococcygeus diffuse or focal muscle abnormality [35].

\section{Limitations of the study}

The study has few limitations. Four panelists who participated in Step 1 and 2 of the study were from the same

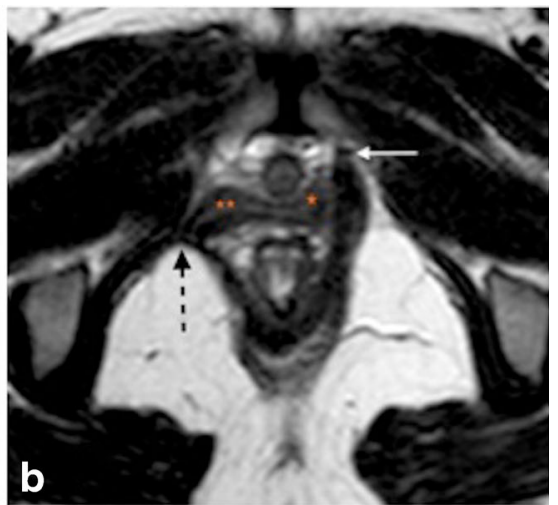

bladder and rectum. The anterior vaginal wall provides urinary bladder support. The posterior vaginal wall and the endopelvic fascia (rectovaginal) form a restraining layer that prevents the rectum from protruding forward. (b) Axial T2W image shows detachment of the puborectalis muscle from its origin identified by discontinuity of its attachment to the pubic bone on the right side (dotted black arrow) (white arrow, normal bony attachment), (** loss of $\mathrm{H}$-shaped vagina on the right side), (*; normal lateral vaginal attachment on the left side)

institution. Therefore, only 1 out of their 4 completed questionnaire was included in the final analysis to avoid biased results. Nevertheless, since all 8 panelists who have completed the questionnaire were from different institutions these recommendations can be considered to represent the entire spectrum of expert opinions in the field of pelvic floor MRI. Second, the recommendations given in this study with regard to technical aspects of MRI of the pelvic floor relate to conventional closedconfiguration magnets for MR imaging allowing patient positioning in lying body position only. However, this is the most agreed upon scanner, in addition several studies have shown that patient positioning does not significantly influence diagnostic performance of MR imaging of the pelvic floor $[17,19,47,48]$.

\section{Conclusion}

Based on an extensive literature review and analysis and of expert consensus, these proposed recommendations can be used as guidance for standardized MR imaging and reporting of PFD. Nevertheless, our joint ESUR-ESGAR pelvic floorworking group is aware about the complexity of the topic and that further studies are mandatory to achieve additional refinements of guidelines for MR imaging, diagnosing and reporting of PFD.

Open Access This article is distributed under the terms of the Creative Commons Attribution 4.0 International License (http:// creativecommons.org/licenses/by/4.0/), which permits unrestricted use, distribution, and reproduction in any medium, provided you give appropriate credit to the original author(s) and the source, provide a link to the Creative Commons license, and indicate if changes were made. 


\section{Appendix 1 Data sheet created to collect the details \\ of the technical protocols of the group members \\ and for literature review}

General

Institution Name

$\begin{array}{ll}\text { Author } & \text { Referrer } \\ & 1=\text { gynecologist } \\ 2 & =\text { urologist } \\ 3 & =\text { proctologist } \\ & 4=\text { other }\end{array}$

Indication for MRI of the pelvic floor

Compartment examined

$1=$ anterior

$2=$ middle

$3=$ posterior

$4=$ anterior and middle

$5=$ all of them

Patient preparation

\begin{tabular}{|c|c|c|c|c|c|c|c|}
\hline $\begin{array}{l}\text { Preparation of } \\
\text { upper GI- } \\
\text { tract } \\
0=\text { no } \\
1=\text { yes }\end{array}$ & $\begin{array}{l}\text { Rectal enema } \\
0=\text { no preparation } \\
1=\text { cleansing } \\
\quad \text { enema }\end{array}$ & $\begin{array}{l}\text { Rectal filling } \\
0=\text { no filling } \\
1=\text { ultrasonic } \\
\text { gel } \\
2=\text { potato starch } \\
3=\text { air }\end{array}$ & $\begin{array}{l}\text { Volume of rectal } \\
\text { filling (ml) }\end{array}$ & $\begin{array}{l}\text { Use of urethral } \\
\text { Folys } \\
\text { catheter } \\
0=\text { no } \\
1=\text { yes }\end{array}$ & $\begin{array}{l}\text { Bladder filling } \\
0=\text { empty } \\
1=\text { moderately } \\
\quad \text { filled } \\
2=\text { full } \\
3=1 \mathrm{~h} \text { void } \\
4=2 \mathrm{~h} \text { void }\end{array}$ & $\begin{array}{l}\text { Vaginal } \\
\text { filling } \\
0=\text { no filling } \\
1=\text { sterile gel } \\
\begin{array}{l}2=\text { normal } \\
\text { gel }\end{array}\end{array}$ & $\begin{array}{l}\text { Use of IV contrast } \\
0=\text { no } \\
1=\text { yes }\end{array}$ \\
\hline
\end{tabular}

Patient instruction and positioning

Patient Training patient positioning

$\begin{array}{ll}0=\text { on grades of straining } & 1=\text { supine } \\ 1=\text { on evacuation } & 2=\text { sitting }\end{array}$

$1=$ on evacuation

$2=$ on withholding
$3=$ lateral right

$4=$ lateral left

$5=$ prone

$6=$ upright patient positioning $0=$ legs side by side

$1=$ legs separated

$2=$ knees elevated

$3=$ upright

$$
\begin{aligned}
& \text { MR scanner } \\
& \text { MR-scanner } \\
& 1=1.0 \mathrm{~T} \\
& 2=1.5 \mathrm{~T} \\
& 3=3 \mathrm{~T} \\
& 4=<1
\end{aligned}
$$

MR-scanner

$0=$ conventional scanner

$1=$ open scanner

2 = upright scanner
Imaging protocol

Static MRI sequences
Dynamic cine MRI sequence

during different patients' maneuvers

Number of phases

$\mathrm{A}=3$ phases (rest, squeezing, strain)

$\mathrm{B}=4$ (rest, squeezing, moderate- max strain)

$\mathrm{C}=5$ (rest, squeezing, mild- moderate -max strain)
MR Defecography

$1=$ real time fluoroscopy

$2=$ multiple repetitions

Geometry (for every sequence)

Sequence Plane FOV (mm)

$1=\mathrm{T} 1 \mathrm{w} \quad 1=$ tra $\quad \operatorname{RFOV}(\%)$

$2=\mathrm{T} 2 \mathrm{w} \quad 2=\mathrm{sag}$ Fold over

$3=$ cor suppression
Matrix scan
Matrix recon-struction Scan per-
centage

Number of slices

Slice thickness

(mm)
Slice gap

orientation
Fold over

\begin{tabular}{|c|c|c|c|c|c|c|c|}
\hline $\begin{array}{l}\text { Scan mode } \\
1=2 \mathrm{D} \\
2=3 \mathrm{D}\end{array}$ & $\begin{array}{l}\text { Technique } \\
1=\mathrm{SE} \\
2=\mathrm{GE}\end{array}$ & Echoes & $\begin{array}{l}\text { TE (msec) } \\
\text { TR (msec) }\end{array}$ & Flip Angle & Half Scan & Number of signal acquisition & Total scan duration \\
\hline
\end{tabular}
direction
REST slabs
$1=$ free
$2=$ parallel

Contrast (for every sequence) 


\section{Appendix 2 Questionnaire for ESUR/ESGAR pelvic floor recommendations}

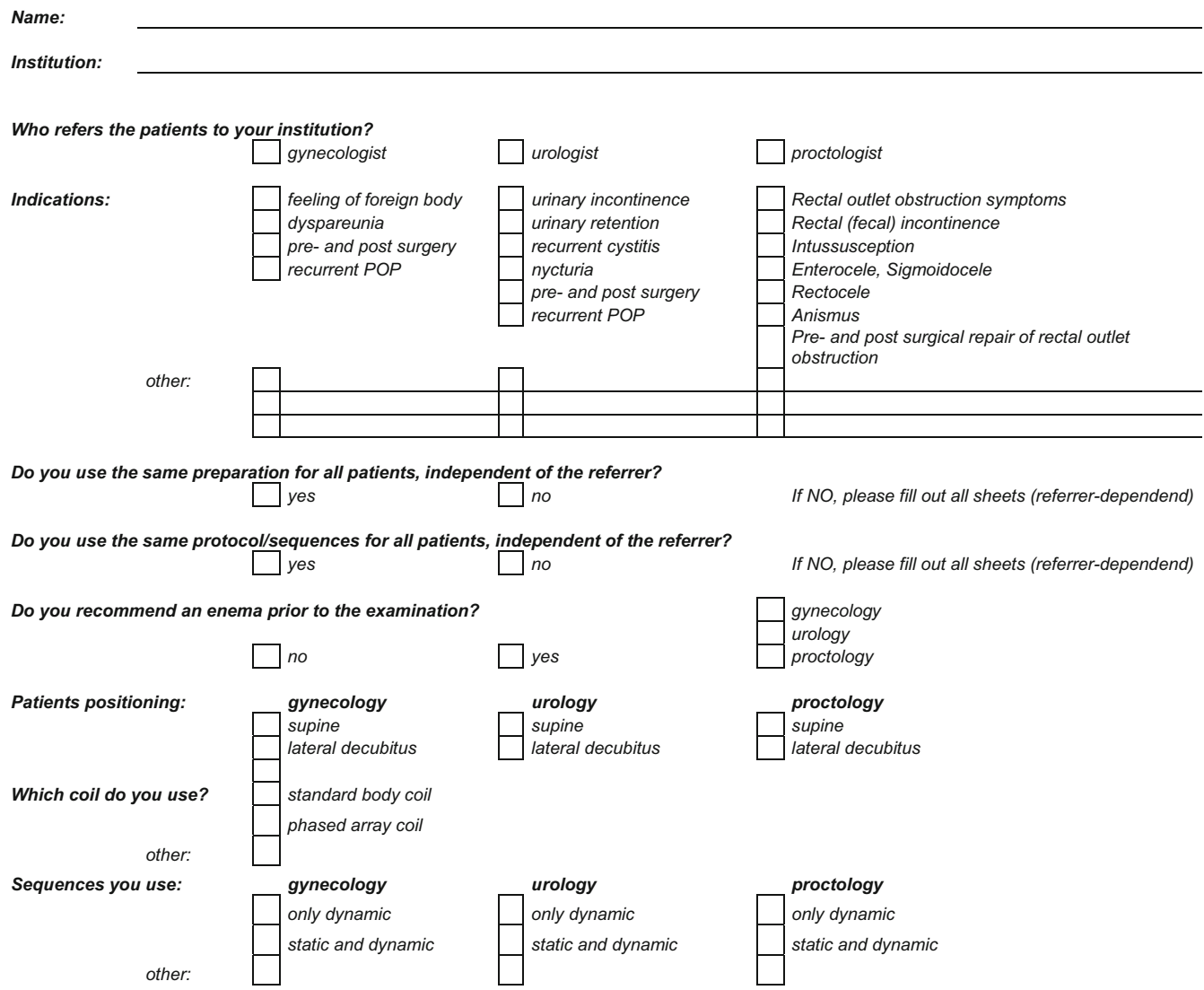

How long takes the dynamic sequence, how many repeating measurements do you perform with how many slices?

MR Scanner used:

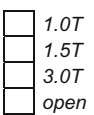

Patients from the GYNECOLOGIST

Preparation

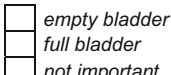

not important

static:

Important sequences

T2 high resolution

other:

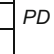

\begin{tabular}{|l} 
squeezing: \\
sag \\
tra \\
cor
\end{tabular}

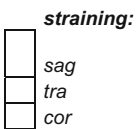

$\square \begin{aligned} & \text { defecation: } \\ & \text { sag } \\ & \text { tra }\end{aligned}$

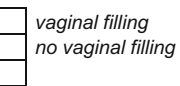

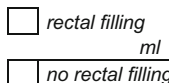

no rectal filling

Angulation:

$\mathrm{ST}(\mathrm{mm}) \quad \mathrm{FOV}(\mathrm{cm})$ first/last slice:

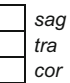

steady-state free precession

(FISP, GRASS, FFE, PSIF, SSFP, T2-FFE)

balanced state free precession (trueFISP, FIESTA, b-FFE)

steady-state free precession

(FISP, GRASS, FFE,PSIF, SSFP, T2-FFE)

balanced state free precession (trueFISP, FIESTA, b-FFE)

teady-state free precession

FISP, GRASS, FFE, PSIF, SSFP, T2-FFE)

balanced state free precession (trueFISP, FIESTA, b-FFE)
$S T(m m) / F O V$

(cm)

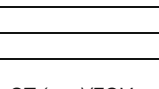

(cm)

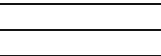

$S T(m m) / F O V$

$(\mathrm{cm})$

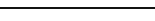


NOTES:

Patients referrred from the UROLOGIST

Preparation

Preparation

mportant sequences

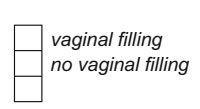

$$
\square \begin{aligned}
& \text { sag } \\
& \text { tra } \\
& \text { cor }
\end{aligned}
$$

T1 high resolution $P D$

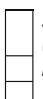

steady-state free precession

FISP, GRASS, FFE, PSIF, SSFP, T2-FFE)

balanced state free precession (trueFISP, FIESTA, b-FFE)

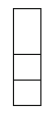

steady-state free precession

(FISP, GRASS, FFE, PSIF, SSFP, T2-FFE)

balanced state free precession (trueFISP, FIESTA, b-FFE)

\begin{tabular}{|l} 
defecation: \\
sag \\
tra \\
cor
\end{tabular}

steady-state free precession

(FISP, GRASS, FFE, PSIF, SSFP, T2-FFE)

balanced state free precession (trueFISP, FIESTA, b-FFE)

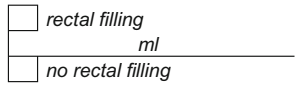

agens:

Angulation:

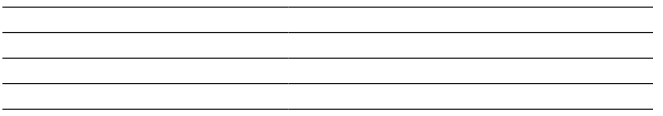

ST $(\mathrm{mm}) / \mathrm{FOV}$

(cm)

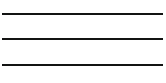

$S T(m m) / F O V$

(cm)

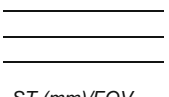

$(\mathrm{cm})$

NOTES:

Patients referred from the PROCTOLOGIST

Preparation

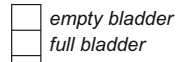

full bladder

not important

static:

T2 high resolution

Important sequences

other:

T1 high resolution

PD

steady-state free precession

(FISP, GRASS, FFE, PSIF, SSFP, T2-FFE)

balanced state free precession (trueFISP, FIESTA, b-FFE)

cor

\begin{tabular}{|l} 
straining: \\
sag \\
tra \\
cor
\end{tabular}

steady-state free precession

(FISP, GRASS, FFE, PSIF, SSFP, T2-FFE)

balanced state free precession (trueFISP, FIESTA, b-FFE)

\begin{tabular}{|l} 
defecation \\
sag \\
tra \\
cor
\end{tabular}

NOTES:

Please list the papers, which are the basis for the protocols and the evaluation in your

institution: 
compartment

s:

anterior \begin{tabular}{ll} 
bladder \\
\cline { 2 - 2 } & urethra
\end{tabular}

reference points/landmarks:

$\begin{array}{ll}\text { anterior: } & \square \begin{array}{l}\text { bladder neck } \\ \text { bladder base }\end{array} \\ & \square \begin{array}{l}\text { anterior cervical lip } \\ \text { middle: }\end{array} \\ & \begin{array}{l}\text { posterior cervical lip } \\ \text { most distal part of cervical lumen } \\ \text { vaginal vault after hysterectomy } \\ \text { posterior peritoneal reflecting fold/lowest part of pouch of } \\ \text { Douglas }\end{array} \\ \text { other: } & \square \begin{array}{l}\text { posterior peritoneal reflecting fold/lowest part of pouch of } \\ \text { pouglas } \\ \text { anterior rectal wall } \\ \text { anterior anorectal wall }\end{array}\end{array}$

reference

line:

\begin{tabular}{|l} 
pubococcygeal line \\
mid pubic line \\
horizontal line \\
PICS line \\
SCIPP line \\
anal line \\
perineal line
\end{tabular}

Definition of endpoint of PCL:

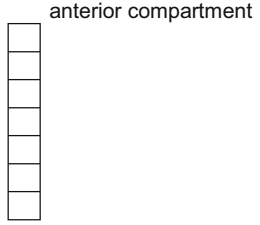

sacrococcygeal joint
lowest margin of os
coccygeus
last coccygeal joint

other:

Definiton of measured values:

reference point above the reference line $\square$ plus sign

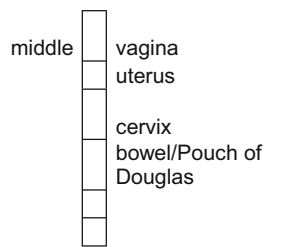

posterior rectum bowel/Pouch of Douglas posterior compartment

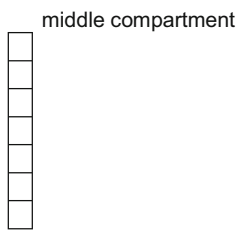

(=SCIPP-line)

\section{nt}


GRADING SYSTEMS:

Do you use different grading systems depending on the reference line?

Do you use different grading sytems depending on the

referrer?

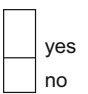

Do you recommend using a grading system at all?

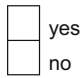

PELVIC ORGAN PROLAPSE (please sign, if you use one of the listed system and for which referrer)

Boyadzhyan, Radiographics 2008

Hecht, AJR 2008

Yang 1991

Haylen, $\mathrm{N}$ and U 2010

Short POP-Q Version AGUB

Colaiacomo, RadioGraphics 2009 (Kelvin AJR 1999)

Woodfield, Int Urogyn J 2009

\begin{tabular}{|c|c|}
\hline Grade 0: & above the $\mathrm{H}$-Line \\
\hline Grade 1: & $0-2 \mathrm{~cm}$ below the $\mathrm{HL}$ \\
\hline Grade 2: & $\begin{array}{l}2-4 \mathrm{~cm} \text { below the } \mathrm{HL} \\
>4 \mathrm{~cm} \text { below the }\end{array}$ \\
\hline Grade 3: & $\mathrm{HL}$ \\
\hline Grade 0: & $\begin{array}{l}<1 \mathrm{~cm} \text { below PCL } \\
1-2 \mathrm{~cm} \text { below }\end{array}$ \\
\hline Grade & $\begin{array}{l}\mathrm{PCL} \\
2-4 \mathrm{~cm} \text { below }\end{array}$ \\
\hline $\begin{array}{l}\text { Grade 2: } \\
\text { Grade 3: }\end{array}$ & $\begin{array}{l}\mathrm{PCL} \\
>4 \mathrm{~cm} \text { below } \mathrm{PCL}\end{array}$ \\
\hline
\end{tabular}

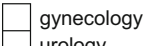

urology

proctology

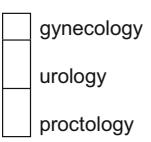

Cystocele: $B$ at least $+1 \mathrm{~cm}$ below PCL

Uterine prolapse: $\mathrm{C} / \mathrm{V}$ at maximum $-1 \mathrm{~cm}$ above $\mathrm{PCL}$

Rectocele: $R$ at least $+2,5 \mathrm{~cm}$ below

PCL

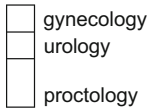

Stage 0:

Stage I:

Stage II:

Stage II:

Stage IV:

No prolapse is demonstrated.

Most distal portion of the prolapse is $>1 \mathrm{~cm}$ above the level of the hymen.

Most distal portion of the prolapse is $\leq 1 \mathrm{~cm}$ proximal to or distal to the hymen

The most distal portion of the prolapse is $>1 \mathrm{~cm}$ below the plane of the hymen

Complete eversion of the total length of the lower genital tract is demonstrated.

\begin{tabular}{|l} 
gynecology \\
urology
\end{tabular}

Grade 0

Grade 1

No prolapse is demonstrated.

proctology

Most distal portion of the prolapse is $>1 \mathrm{~cm}$ above the level of the hymen.

Most distal portion of the prolapse reaches the introitus

Grade 2

Grade 3

Most dital portion of the prolapse is $>2 \mathrm{~cm}$ below the introitus

Complete eversion of the total length of the lower genital tract is demonstrated.

gynecology

urology

proctology

Cystocele

Grade 0:

Grade 1:

Grade 2:

Grade 3 :

$\square$ Vaginal Vault

Grade 0:

Grade 1:

Grade 2:

Grade 3:

$\square$ Rectocele

Grade 0:

Grade 1:

Grade 2:

Grade 3:

up to $+1 \mathrm{~cm}$ below $\mathrm{PCL}$

+1 to $+3 \mathrm{~cm}$ below PCL

+3 to $+6 \mathrm{~cm}$ below $\mathrm{PCL}$

$>+6 \mathrm{~cm}$ below $\mathrm{PCL}$

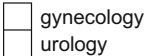

urology

above PCL

0 to $+3 \mathrm{~cm}$ below $\mathrm{PCL}$

+3 to $+6 \mathrm{~cm}$ below $\mathrm{PCL}$

$>+6 \mathrm{~cm}$ below $\mathrm{PCL}$

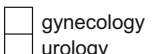

urology

proctology

no outpouching

outpouching up to $2 \mathrm{~cm}$

outpouching between 2 and $4 \mathrm{~cm} \quad \square$ proctology

outpouching $>4 \mathrm{~cm}$

above PCL

descent $<3 \mathrm{~cm}$ below PCL

descent $3-6 \mathrm{~cm}$ below PCL

descent $3-6 \mathrm{~cm}$ below PCL
descent $>6 \mathrm{~cm}$ below PCL

complete organ prolapse

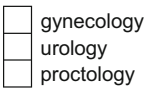

Grade 1:

Grade 2:

Grade 3:

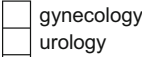

urology

Grade 0: no descent

Grade 1: descent to $1 \mathrm{~cm}$ proximal to

MPL

Grade 2: descent between $1 \mathrm{~cm}$ proximal and distal MPL

Grade 3: descent between $1 \mathrm{~cm}$ distal MPLand $2 \mathrm{~cm}-\mathrm{TVL}$

Grade 4: descent from $2 \mathrm{~cm}-\mathrm{TVL}$ to complete prolapse

other:

NOTES: 
PELVIC FLOOR RELAXATION (please sign, if you use the listed system and for which referrer)

Boyadzhyan, Radiographics 2008

enlargement hiatus

descent $\mathrm{H}$-line to $\mathrm{PCL}$ (=M-line)

$\begin{array}{ll}\text { Grade 0 } & <6 \mathrm{~cm} \\ \text { Grade 1 } & 6-8 \mathrm{~cm} \\ & 8-10 \\ \text { Grade 2 } & \mathrm{cm} \\ & >10 \\ \text { Grade 3 } & \mathrm{cm}\end{array}$

Grade $0 \quad 0-2 \mathrm{~cm}$

Grade $1 \quad 2-4 \mathrm{~cm}$

Grade 2 4-6 cm

Grade $3>6 \mathrm{~cm}$

gynecology

urology

proctology

other:

NOTES:

\section{References}

1. Jacobsen LA, Kent M, Lee M, Mather M (2011) America's aging population. Popul Bull 66:1-18

2. Gerten KA, Markland AD, Lloyd LK, Richter HE (2008) Prolapse and incontinence surgery in older women. J Urol 179:2111-2118

3. Samuelsson EC, Victor A, Tibblin G, Svardsudd KF (1999) Signs of genital prolapse in a Swedish population of women 20 to 59 years of age and possible related factors. Am J Obstet Gynecol 180:299-305

4. Boyadzhyan L, Raman SS, Raz S (2008) Role of static and dynamic MR imaging in surgical pelvic floor dysfunction. Radiographics 28:949-967

5. Comiter CV, Vasavada SP, Barbaric ZL et al (1999) Grading pelvic prolapse and pelvic floor relaxation using dynamic magnetic resonance imaging. Urology 54:454-457

6. Hoyte L, Schierlitz L, Zou K et al (2001) Two- and 3-dimensional MRI comparison of levator ani structure, volume, and integrity in women with stress incontinence and prolapse. Am J Obstet Gynecol 185:11-19

7. Maglinte DD, Kelvin FM, Fitzgerald K et al (1999) Association of compartment defects in pelvic floor dysfunction. AJR Am J Roentgenol 172:439-444

8. Alt CD, Brocker KA, Lenz F et al (2014) MRI findings before and after prolapse surgery. Acta Radiol 55:495-504

9. Etlik O, Arslan H, Odabasi O et al (2005) The role of the MRfluoroscopy in the diagnosis and staging of the pelvic organ prolapse. Eur J Radiol 53:136-141

10. Grassi R, Lombardi G, Reginelli A et al (2007) Coccygeal movement: assessment with dynamic MRI. Eur J Radiol 61: 473-479

11. Gufler H, DeGregorio G, Dohnicht S et al (2002) Dynamic MRI after surgical repair for pelvic organ prolapse. J Comput Assist Tomogr 26:734-739

12. El Sayed RF, Fielding JR, El Mashed S et al (2005) Preoperative and postoperative magnetic resonance imaging of female pelvic floor dysfunction: correlation with clinical findings. J Women's Imag 7:163-180
13. Kaufman HS, Buller JL, Thompson JR et al (2001) Dynamic pelvic magnetic resonance imaging and cystocolpoproctography alter surgical management of pelvic floor disorders. Dis Colon Rectum 44: 1574-1575

14. Betschart C, Chen L, Ashton-Miller JA, Delancey JO (2013) On pelvic reference lines and the MR evaluation of genital prolapse: a proposal for standardization using the Pelvic Inclination Correction System. Int Urogynecol J 24:1421-1428

15. El Sayed RF, El Mashed S, Farag A et al (2008) Pelvic floor dysfunction: assessment with combined analysis of static and dynamic MR imaging findings. Radiology 248:518-530

16. Maccioni F (2013) Functional disorders of the ano-rectal compartment of the pelvic floor: clinical and diagnostic value of dynamic MRI. Abdom Imaging 38:930-951

17. Fielding JR, Versi E, Mulkern RV et al (1996) MR imaging of the female pelvic floor in the supine and upright positions. J Magn Reson Imaging 6:961-963

18. Bartram CI, Goh V, Halligan S et al (2000) Dynamic MR imaging of the pelvic floor in asymptomatic subjects. AJR Am J Roentgenol 174:661-666

19. Fielding JR, Griffiths DJ, Versi E et al (1998) MR imaging of pelvic floor continence mechanisms in the supine and sitting positions. Am J Roentgenol 171:1607-1610

20. Elshazly WG, El Nekady AA, Hassan H (2010) Role of dynamic magnetic resonance imaging in management of obstructed defecation case series. Int J Surg 8:274-282

21. Nichols DH, Randall CL (1989) Vaginal surgery. Williams \& Wilkins, Baltimore

22. Bertschinger KM, Hetzer FH, Roos JE et al (2002) Dynamic MR imaging of the pelvic floor performed with patient sitting in an open-magnet unit versus with patient supine in a closed-magnet unit. Radiology 223:501-508

23. Elsayed RF (2015) Pelvic floor imaging. In: Shaaban AM (ed) Diagnostic imaging gynecol, 2nd edn. Elsevier, Amirsys, pp 8/ 30-8/39

24. Felt-Bersma RJ, Cuesta MA (2001) Rectal prolapse, rectal intussusception, rectocele, and solitary rectal ulcer syndrome. Gastroenterol Clin North Am 30:199-222 
25. Singh K, Jakab M, Reid WM et al (2003) Three-dimensional magnetic resonance imaging assessment of levator ani morphologic features in different grades of prolapse. Am J Obstet Gynecol 188:910-915

26. Mortele KJ, Fairhurst J (2007) Dynamic MR defecography of the posterior compartment: indications, techniques and MRI features. Eur J Radiol 61:462-472

27. Shorvon PJ, McHugh S, Diamant NE et al (1989) Defecography in normal volunteers: results and implications. Gut 30:1737-1749

28. Morren GL, Balasingam AG, Wells JE et al (2005) Triphasic MRI of pelvic organ descent: sources of measurement error. Eur J Radiol $54: 276-283$

29. Halligan S, Bartram CI, Park HJ, Kamm MA (1995) Proctographic features of anismus. Radiology 197:679-682

30. Broekhuis SR, Kluivers KB, Hendriks JC et al (2009) Dynamic magnetic resonance imaging: reliability of anatomical landmarks and reference lines used to assess pelvic organ prolapse. Int Urogynecol J Pelvic Floor Dysfunct 20:141-148

31. Elsayed RF (2015) Middle compartment. In: Shaaban AM (ed) Diagnostic imaging gynecol, 2nd edn. Elsevier, Amirsys, pp 8/ $68-8 / 88$

32. Woodfield CA, Krishnamoorthy S, Hampton BS, Brody JM (2010) Imaging pelvic floor disorders: trend toward comprehensive MRI. AJR Am J Roentgenol 194:1640-1649

33. Kelvin FM, Maglinte DD, Hornback JA, Benson JT (1992) Pelvic prolapse: assessment with evacuation proctography (defecography). Radiology 184:547-551

34. Bump RC, Mattiasson A, Bo K et al (1996) The standardization of terminology of female pelvic organ prolapse and pelvic floor dysfunction. Am J Obstet Gynecol 175:10-17

35. Alt CD, Hampel F, Hallscheidt P, et al. (2014) 3 T MRI-based measurements for the integrity of the female pelvic floor in 25 healthy nulliparous women. Neurourol Urodyn

36. Halligan S, Bartram C, Hall C, Wingate J (1996) Enterocele revealed by simultaneous evacuation proctography and peritoneography: does "defecation block" exist? Am J Roentgenol 167:461-466

37. Healy JC, Halligan S, Reznek RH et al (1997) Dynamic MR imaging compared with evacuation proctography when evaluating anorectal configuration and pelvic floor movement. Am J Roentgenol 169:775-779

38. Elsayed RF (2015) Overview of posterior compartemnt. In: Shaaban AM (ed) Diagnostic imaging gynecol, 2nd edn. Elsevier, Amirsys, pp 8/88-8/101

39. Yang A, Mostwin JL, Rosenshein NB, Zerhouni EA (1991) Pelvic floor descent in women: dynamic evaluation with fast MR imaging and cinematic display. Radiology 179:25-33

40. Fletcher JG, Busse RF, Riederer SJ et al (2003) Magnetic resonance imaging of anatomic and dynamic defects of the pelvic floor in defecatory disorders. Am J Gastroenterol 98:399-411

41. Woodfield CA, Hampton BS, Sung V, Brody JM (2009) Magnetic resonance imaging of pelvic organ prolapse: comparing pubococcygeal and midpubic lines with clinical staging. Int Urogynecol J Pelvic Floor Dysfunct 20:695-701

42. Elsayed RF (2015) Anterior compartment. In: Shaaban AM (ed) Diagnostic imaging gynecol, 2nd edn. Elsevier, Amirsys, pp 8/ $40-8 / 68$

43. Kruyt RH, Delemarre JB, Doornbos J, Vogel HJ (1991) Normal anorectum: dynamic MR imaging anatomy. Radiology 179:159163

44. Lienemann A, Sprenger D, Janssen U et al (2004) Assessment of pelvic organ descent by use of functional cine-MRI: which reference line should be used? Neurourol Urodyn 23:33-37

45. Schreyer AG, Paetzel C, Fürst A et al (2012) Dynamic magnetic resonance defecography in 10 asymptomatic volunteers. World $\mathrm{J}$ Gastroenterol 18:6836-6842

46. Shorvon PJ, Marshall MM (2005) Evacuation proctography. complex anorectal. Disord Investig Manag

47. El-Sayed RF, Morsy MM, el-Mashed SM, Abdel-Azim MS (2007) Anatomy of the urethral supporting ligaments defined by dissection, histology, and MRI of female cadavers and MRI of healthy nulliparous women. AJR Am J Roentgenol 189:1145-1157

48. Huddleston HT, Dunnihoo DR, Huddleston PM 3rd, Meyers PC Sr (1995) Magnetic resonance imaging of defects in DeLancey's vaginal support levels I, II, and III. Am J Obstet Gynecol 172:17741778 